Research Article

\title{
Electrical Properties of Amorphous Titanium Oxide Thin Films for Bolometric Application
}

\author{
Yongfeng Ju, Mahua Wang, Yunlong Wang, Shihu Wang, and Chengfang Fu
}

Faculty of Electronic and Electrical Engineering, Huaiyin Institute of Technology, Huaian 223003, China

Correspondence should be addressed to Yongfeng Ju; yfu_ha@163.com

Received 1 August 2013; Accepted 15 October 2013

Academic Editor: Xia Xiang

Copyright (C) 2013 Yongfeng Ju et al. This is an open access article distributed under the Creative Commons Attribution License, which permits unrestricted use, distribution, and reproduction in any medium, provided the original work is properly cited.

\begin{abstract}
We report the electrical conduction mechanism of amorphous titanium oxide thin films applied for bolometers. As the $\mathrm{O} / \mathrm{Ti}$ ratio varies from 1.73 to 1.97 measured by rutherford backscattering spectroscopy, the resistivity of the films increases from $0.26 \Omega \mathrm{cm}$ to $10.1 \Omega \mathrm{cm}$. At the same time, the temperature coefficient of resistivity and activation energy vary from $-1.2 \%$ to $-2.3 \%$ and from $0.09 \mathrm{eV}$ to $0.18 \mathrm{eV}$, respectively. The temperature dependence of the electrical conductivity illustrates a thermally activated conduction behavior and the carrier transport mechanism in the titanium oxide thin films is found to obey the normal MeyerNeldel Rule in the temperature range from 293 K to 373 K.
\end{abstract}

\section{Introduction}

Titanium dioxide $\left(\mathrm{TiO}_{2}\right)$ is one of the most widely studied transition metal oxide semiconductors due to its nontoxic nature, chemical stability, and commercial availability at a low cost, robust, and general reactivity. During the past decades, $\mathrm{TiO}_{2}$ thin films have attracted much interest because it has a wide range of promising energy and environmental applications, such as hydrogen generation by water splitting [1], photocatalytic water purification [2], dye-sensitized solar cells [3], and gas sensors [4]. Recently, few people have fabricated amorphous nonstoichiometric titanium dioxide, (a- $\mathrm{TiO}_{x}$, where $x$ is smaller than 2) thin films by different methods and pointed out that $\mathrm{a}-\mathrm{TiO}_{x}$ thin films are potential thermal sensing material for an uncooled IR bolometer imager [5]. However, the effect of the deposition process on the film structure, composition and electrical properties of this material such as resistivity, temperature coefficient of resistivity (TCR), and activation energy, have not been illustrated up to now, and these factors are very crucial for the detectivity of thermal IR detectors.

$\mathrm{TiO}_{x}$ thin films can be prepared by sol-gel [6], hydrothermal [7], chemical and physical vapor deposition [8]. Reactive sputtering is a commonly used physical vapor deposition method to grow dense and uniform metal oxide films for industrial application $[9,10]$. In this process, a metal target is sputtered in an atmosphere consisting of argon and oxygen, this allows higher deposition rates than does the sputtering of an oxide target [10]. It has been experimentally established that the oxygen partial pressure $\left(\mathrm{pO}_{2}\right)$ during sputtering has the most significant effect on the structure, phase composition, and electrical properties of $\mathrm{TiO}_{x}$ thin films [11].

$\mathrm{TiO}_{2}$ is electrically insulating with an extremely high resistivity above $10^{8} \Omega \mathrm{cm}$, but the suboxidized $\mathrm{TiO}_{2}$ with an excess of titanium is an $\mathrm{n}$ type semiconductor with unique properties [12], indicating the defect disorder and O/Ti stoichiometry play an important role in the electrical properties of $\mathrm{TiO}_{x}$ [13]. In this work, we have mainly investigated the electrical properties and electron transport mechanism of a$\mathrm{TiO}_{x}$ thin films applied for uncooled IR thermal detectors.

\section{Experimental}

$\mathrm{TiO}_{x}$ thin films were deposited on $\mathrm{K} 9$ glass and p-silicon (100) substrates simultaneously at room temperature by a dc reactive sputtering technique. Oxygen and argon were used as reactive gas and sputtering gas, respectively. The total pressure was kept at $1 \mathrm{~Pa}$ and the other characteristic parameters of the investigated samples are summarized in Table 1. 
TABLE 1: Experimental parameters of reactive sputtering and the results of measurements. (SCCM is an abbreviation of standard cubic centimeter per minute).

\begin{tabular}{lcccccccc}
\hline Samples & $\operatorname{Ar}(\mathrm{SCCM})$ & $\begin{array}{c}\mathrm{O}_{2} /\left(\mathrm{O}_{2}+\mathrm{Ar}\right) \\
\left(\mathrm{pO}_{2}\right)\end{array}$ & $\begin{array}{c}\text { Thickness } d \\
(\mathrm{~nm})\end{array}$ & $\mathrm{O} / \mathrm{Ti}$ ratio & $\begin{array}{c}\text { Resistivity } \rho \\
(\Omega \mathrm{cm})\end{array}$ & $\begin{array}{c}\text { Conductivity } \\
\sigma\left(\Omega^{-1} \mathrm{~cm}^{-1}\right)\end{array}$ & $\begin{array}{c}\text { Activation } \\
\text { energy } E_{a}(\mathrm{eV})\end{array}$ & $\begin{array}{l}|\mathrm{TCR}|(\%) \\
\text { S10 }\end{array}$ \\
\hline S25 & 80 & $1.0 \%$ & 101 & 1.73 & 0.26 & 3.85 & 0.09 & 1.2 \\
S40 & 80 & $2.5 \%$ & 100 & 1.84 & 1.9 & 0.53 & 0.15 & 1.9 \\
S55 & 80 & $4.0 \%$ & 98 & 1.91 & 3.1 & 0.32 & 0.16 & 2.0 \\
\hline
\end{tabular}

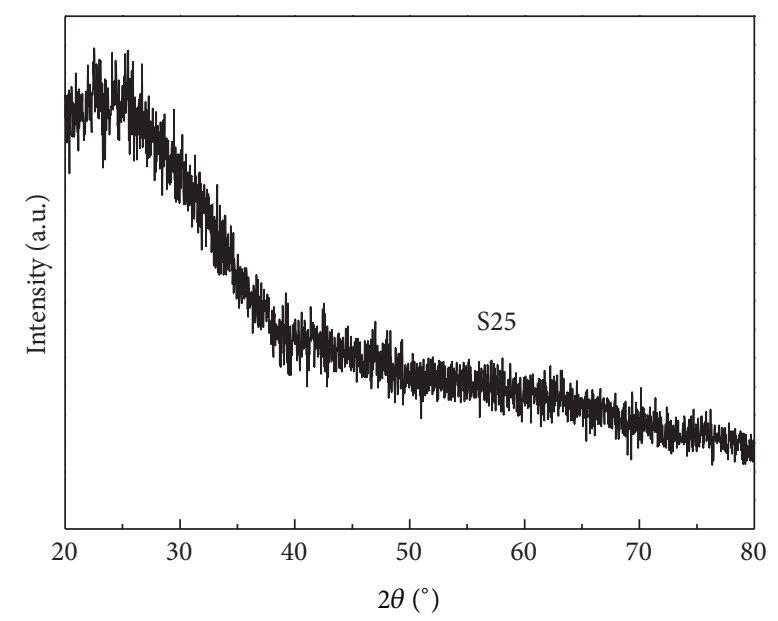

FIGURE 1: XRD pattern of $\mathrm{TiO}_{x}$ thin film (S25) deposited at the $\mathrm{pO}_{2}$ of $1.5 \%$.

The thickness and surface morphology of the films were characterized by field emission scanning electron microscopy (FESEM, Hitachi S4800). Glancing incidence X-ray diffraction (GIXRD, PANalytical X'Pert PRO) was performed by using $\mathrm{Cu} K \alpha$ radiation $(0.1564 \mathrm{~nm})$ with a glancing incidence of $2^{\circ}, U=40 \mathrm{kV}$ and $I=35 \mathrm{~mA}$. The O/Ti stoichiometry of the films was measured by rutherford backscattering spectrometry (RBS, NEC 5SDH-2) performed with a $2.023 \mathrm{MeV}^{4} \mathrm{He}^{+}$beam from a $2 \times 1.7 \mathrm{MV}$ tandem accelerator. The temperature dependent electrical measurements were performed with a semiconductor characterization system (Keithley, 4200-SCS) in a temperature controller (Sigma Systems, Sigma C4) with an accuracy of $0.1^{\circ}$.

\section{Results and Discussion}

The GIXRD pattern for sample S25 is shown in Figure 1. The patterns of the other three samples have similar characteristics as S25. No sharp diffraction peak of any crystalline phase is observed, which indicates all the films deposited at room temperature have amorphous structure, with no preferred orientation as demonstrated in the previous studies $[5,14,15]$.

Figure 2 presents the cross-sectional and surface morphological micrographs of sample S25, which shows that the thickness of the $\mathrm{TiO}_{x}$ film is about $100 \mathrm{~nm}$, and the film is dense and smooth, which is the advantage of sputtering technique compared with other deposition methods [10].
Furthermore, no grain or cluster appears in the films, this confirms the amorphous structure of the films.

Figure 3 shows a typical experimental RBS spectrum of titanium oxide films (S25) deposited on p-silicon (100) substrate with the simulated spectrum using the program SIMNRA [16]. The O/Ti stoichiometry across the films have been obtained by simulating the experimental spectrum (circle) and theoretical spectrum (line). The results presented in Table 1 show the O/Ti ratio is in accordance with the $\mathrm{pO}_{2}$, and all the films have nonstoichiometry compositions.

Figure 4 shows the electrical resistivity $(\rho)$ of $\mathrm{TiO}_{x}$ films as a function of temperature. As is seen, the resistivity is significantly influenced by the $\mathrm{pO}_{2}$ during the deposition process. The resistivity measured at room temperature increases from $0.26 \Omega \mathrm{cm}$ to $10.1 \Omega \mathrm{cm}$ as the $\mathrm{pO}_{2}$ increases from $1 \%$ to $5.5 \%$. This can be explained by the decrease of oxygen vacancies in the $\mathrm{TiO}_{x}$ films with the increasing $\mathrm{pO}_{2}$ [17], resulting in an increase of $\mathrm{O} / \mathrm{Ti}$ ratio as illustrated by RBS analysis. Thus the larger resistivity is obtained [12]. The electrical resistivity $(\rho)$ or conductivity $(\sigma)$ of the broad-band semiconductors can be expressed as follows [18]:

$$
\begin{gathered}
\rho=\rho_{a} \exp \left(\frac{E_{a}}{k T}\right), \\
\sigma=\sigma_{a} \exp \left(-\frac{E_{a}}{k T}\right),
\end{gathered}
$$

where $E_{a}$ is the thermal activation energy, $k$ is the Boltzmann constant, $T$ is the absolute temperature, and the preexponential factors $\rho_{a}$ and $\sigma_{a}$ are the resistivity at $T \rightarrow \infty$ and conductivity at $T \rightarrow 0$, respectively. As can be seen in Figure 4, the curves exhibit Arrhenius characteristics in accordance with equation (1a) [19].

From the temperature dependence of electrical conductivity plotted as $\ln \sigma$ versus $10^{3} / T$ shown in Figure 5 , the activation energies of $\mathrm{TiO}_{x}$ films can be calculated from the slopes of the fitted lines by equation (1b), and the results are presented in Table 1 show that the activation energy increases from $0.09 \mathrm{eV}$ to $0.18 \mathrm{eV}$ with the increasing resistivity. With the activation energies, the temperature coefficient of resistivity (TCR) can be obtained and TCR is extensively exploited as one of the most important parameters characterizing the detectivity of uncooled IR sensors, defined as the slope of natural logarithm resistivity [20]:

$$
\mathrm{TCR}=\left(\frac{1}{\rho}\right) \times\left(\frac{d \rho}{d T}\right) .
$$




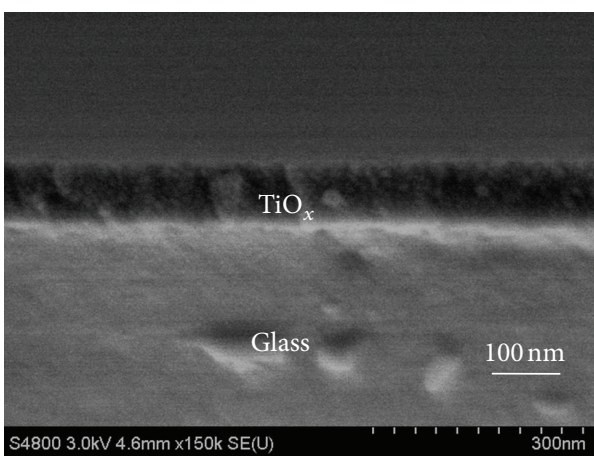

(a)

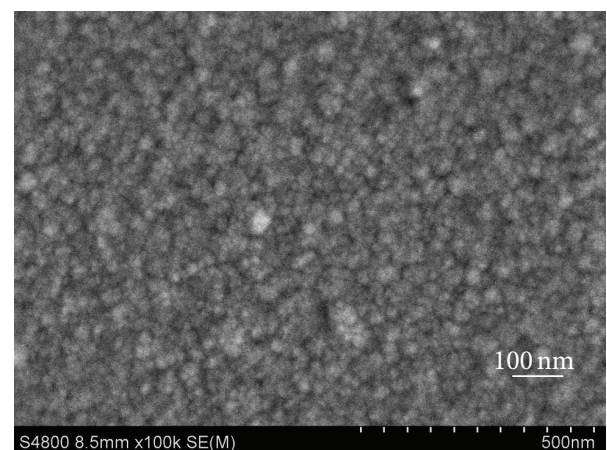

(b)

FIGURE 2: FESEM micrographs of sample S25 (the other samples are alike): (a) cross-section and (b) surface morphology.

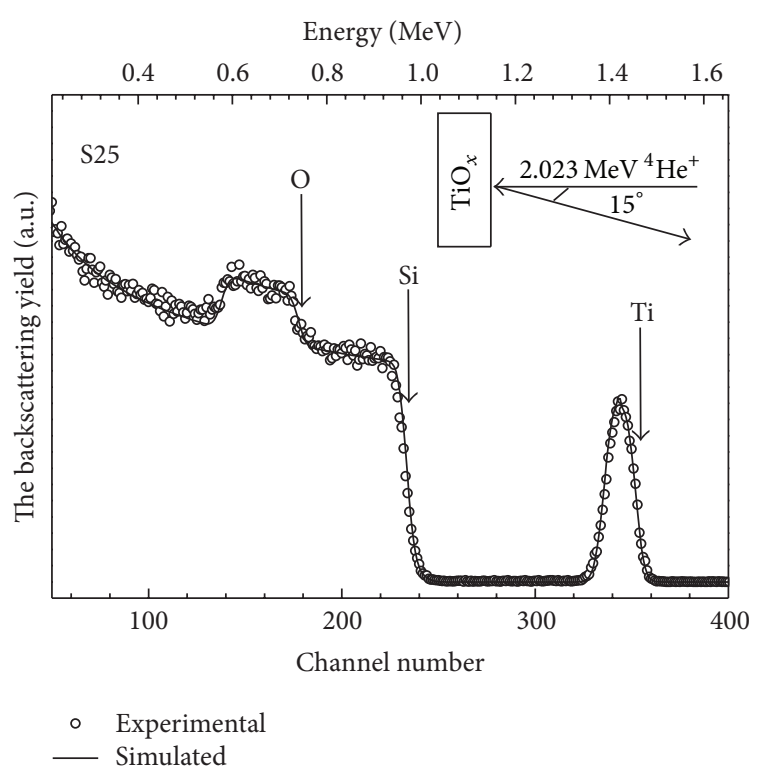

Figure 3: RBS spectrum of $\mathrm{TiO}_{x}$ thin film (S25) on p-Si (100) substrate.

Combing equation (1a) and equation (2), we can yield

$$
E_{a}=-k T^{2} \times \mathrm{TCR}
$$

This relation links the activation energy $E_{a}$ to TCR. With the calculated values of $E_{a}$, the TCR of the $\mathrm{TiO}_{x}$ films can be deduced from equation (3), and the absolute values of TCR are found to increase from $1.2 \%$ for to $2.3 \%$ as the $\mathrm{pO}_{2}$ increase from $1 \%$ to $5.5 \%$, respectively. This is due to the fact that the increase in oxygen during deposition can result in its direct incorporation into the films. Accordingly, an increased oxidation state could be expected to compensate the oxygen deficiency in the $\mathrm{TiO}_{x}$ films, and the electron concentration in the film decreases, which will cause an increase of the activation. As a result, absolute value of TCR increases [21].

In fact, for $\mathrm{TiO}_{2}$ semiconductor thin films having broad energy gap about $3.0 \mathrm{eV}$, the contribution of impurity band conduction may become significant [22]. Mardare et al. have investigated the electrical properties of polycrystalline

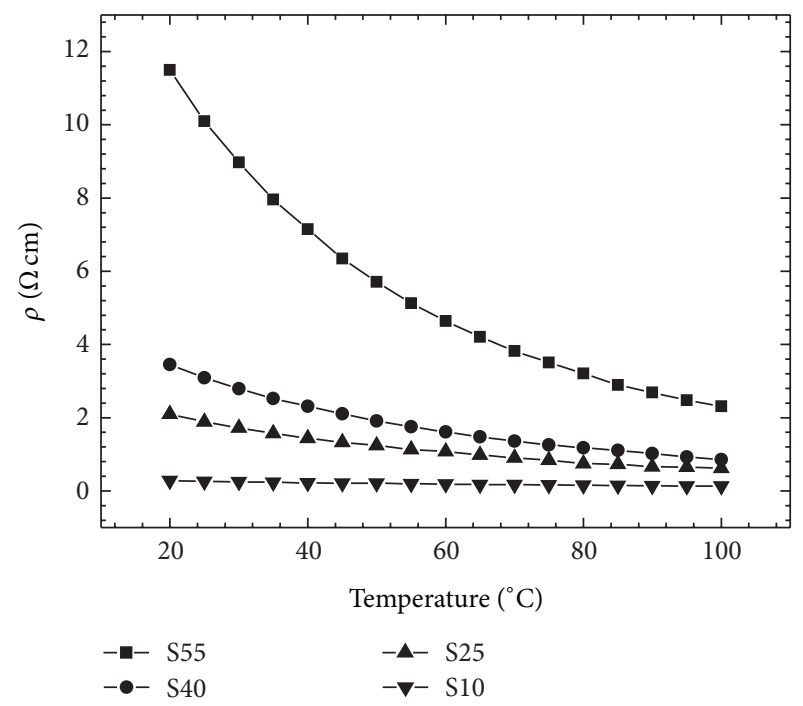

FIgURE 4: Temperature dependence of resistivity $\rho$ in the temperature range from $20^{\circ} \mathrm{C}$ to $100^{\circ} \mathrm{C}$.

$\mathrm{TiO}_{x}$ thin films containing a mixed phase of anatase and rutile, and they point out that at high temperatures $(T>$ $300 \mathrm{~K}$ ), the measured conductivity of $\mathrm{TiO}_{x}$ thin films can also be explained in terms of the simple thermally activated conduction mechanism, but at low temperatures $(T<300 \mathrm{~K})$, the conductivity takes place through the electrons' variable range of hopping (VRH) between the localized states, and the activation energy of hopping is much smaller than that of the simple activated conduction [18]. However, they did not investigate the electrical transport properties of the a$\mathrm{TiO}_{x}$ thin films, and the conduction mechanism is not clear yet. From the linear characteristics of the curves plotted as $\ln \sigma$ versus $10^{3} / T$ in Figure 5, the mechanism of electrical conduction in $\mathrm{a}-\mathrm{TiO}_{x}$ thin films can be explained according to the thermally activated mode in the temperature domain $293 \mathrm{~K}$ to $373 \mathrm{~K}$, as illustrated by equation (1b).

Furthermore, we have found that the pre-exponential factors $\sigma_{a}$ of $\mathrm{TiO}_{x}$ thin films exhibits an exponential dependence as functions of the activation energies, as presented 


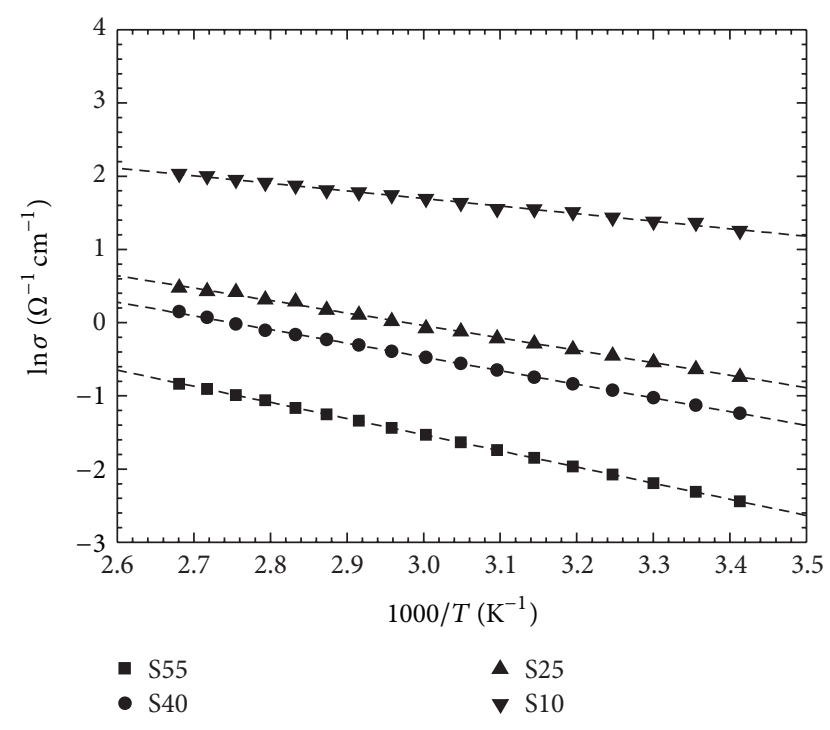

Figure 5: Temperature dependence of conductivity $\sigma$ plotted as $\ln \sigma$ versus $10^{3} / \mathrm{T}$ in the range between $293 \mathrm{~K}$ and $373 \mathrm{~K}$.

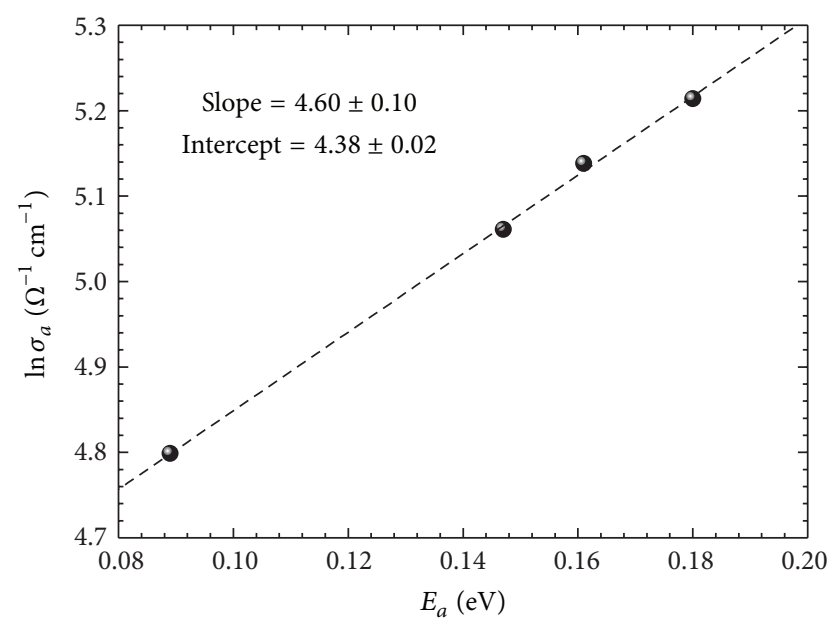

FIgURE 6: Preexponential factors $\sigma_{a}$ as a function of activation energies $E_{a}$ of $\mathrm{TiO}_{x}$ films deposited at various $\mathrm{pO}_{2}$.

in Figure 6 . The data can be fitted linearly by the following function:

$$
\ln \sigma_{a}=\ln \sigma_{a 0}+\frac{E_{a}}{E_{\mathrm{MN}}},
$$

where $\sigma_{a 0}$ and $E_{\mathrm{MN}}$ are constants, called the Meyer-Nedel pre-exponential factor and characteristic energy, respectively. This relation can also be written as

$$
\sigma_{a}=\sigma_{a 0} \exp \left(\frac{E_{a}}{E_{\mathrm{MN}}}\right) .
$$

This is called the Meyer-Neldel Rule (MNR) because it was first pointed out by Meyer and Neldel in 1937 [23], and the relation gives the dependence of the pre-exponential factor $\sigma_{a}$ on the activation energy $E_{a}$. Although it is an empirical relation (also called as the compensation rule), the MNR has been frequently observed in a wide variety of condensed matter, particularly in disordered, amorphous, and nanocrystalline materials that exhibit a thermally activated behavior, such as amorphous silicon [24], chalcogenide glasses [25, 26], liquid semiconductors [27], and polymers [28]. As shown in Figure 6, the $\sigma_{a}$ increases with the increasing $E_{a}$, indicating the electrical conductivity in amorphous $\mathrm{TiO}_{x}$ thin films deposited obeys the normal MNR but not inverse MNR [29].

\section{Conclusion}

Amorphous $\mathrm{TiO}_{x}\left(\mathrm{a}-\mathrm{TiO}_{x}\right)$ thin films for bolometric application have been fabricated at room temperature using a dc reactive sputtering technique. The $\mathrm{O} / \mathrm{Ti}$ ratio changes from 1.73 to 1.97 , and the resistivity of the samples varies from $0.26 \Omega \mathrm{cm}$ to $10.1 \Omega \mathrm{cm}$ and TCR from $-1.2 \%$ to $-2.3 \%$ with different oxygen partial pressures. It has been demonstrated that the dependence of electrical conductivity of the films exhibits a thermally activated behavior in the temperature range from $293 \mathrm{~K}$ to $373 \mathrm{~K}$. Furthermore, it is also found that the electron transport mechanism in the $\mathrm{a}^{\mathrm{TiO}} \mathrm{TiO}_{x}$ obeys the well-known normal Meyer-Neldel Rule.

\section{References}

[1] A. Fujishima and K. Honda, "Electrochemical photolysis of water at a semiconductor electrode," Nature, vol. 238, no. 5358, pp. 37-38, 1972.

[2] M. R. Hoffmann, S. T. Martin, W. Choi, and D. W. Bahnemann, "Environmental applications of semiconductor photocatalysis," Chemical Reviews, vol. 95, no. 1, pp. 69-96, 1995.

[3] B. O’Regan and M. Grätzel, "A low-cost, high-efficiency solar cell based on dye-sensitized colloidal $\mathrm{TiO}_{2}$ films," Nature, vol. 353, no. 6346, pp. 737-740, 1991.

[4] B. Karunagaran, P. Uthirakumar, S. J. Chung, S. Velumani, and E.-K. Suh, " $\mathrm{TiO}_{2}$ thin film gas sensor for monitoring ammonia," Materials Characterization, vol. 58, no. 8-9, pp. 680-684, 2007.

[5] A. L. Lin, "Bolometer having an amorphous titanium oxide layer with high resistance stability," U.S. Patent 7442933, 2008.

[6] A. Verma, A. Basu, A. K. Bakhshi, and S. A. Agnihotry, "Structural, optical and electrochemical properties of sol-gel derived $\mathrm{TiO}_{2}$ films: annealing effects," Solid State Ionics, vol. 176, no. 29-30, pp. 2285-2295, 2005.

[7] A. Testino, I. R. Bellobono, V. Buscaglia et al., "Optimizing the photocatalytic properties of hydrothermal $\mathrm{TiO}_{2}$ by the control of phase composition and particle morphology. A systematic approach," Journal of the American Chemical Society, vol. 129, no. 12, pp. 3564-3575, 2007.

[8] X. Chen and S. S. Mao, "Titanium dioxide nanomaterials: synthesis, properties, modifications and applications," Chemical Reviews, vol. 107, no. 7, pp. 2891-2959, 2007.

[9] T. Kubart, O. Kappertz, T. Nyberg, and S. Berg, "Dynamic behaviour of the reactive sputtering process," Thin Solid Films, vol. 515, no. 2, pp. 421-424, 2006.

[10] S. Berg and T. Nyberg, "Fundamental understanding and modeling of reactive sputtering processes," Thin Solid Films, vol. 476, no. 2, pp. 215-230, 2005.

[11] D. Wicaksana, A. Kobayashi, and A. Kinbara, "Process effects on structural properties of $\mathrm{TiO}_{2}$ thin films by reactive sputtering," 
Journal of Vacuum Science and Technology A, vol. 10, pp. 14791482, 1992.

[12] R. G. Breckenridge and W. R. Hosler, "Electrical properties of titanium dioxide semiconductors," Physical Review, vol. 91, no. 4, pp. 793-802, 1953.

[13] J. Nowotny, T. Bak, M. K. Nowotny, and L. R. Sheppard, "Titanium dioxide for solar-hydrogen II. Defect chemistry," International Journal of Hydrogen Energy, vol. 32, no. 14, pp. 2630-2643, 2007.

[14] P. Löbl, M. Huppertz, and D. Mergel, "Nucleation and growth in $\mathrm{TiO}_{2}$ films prepared by sputtering and evaporation," Thin Solid Films, vol. 251, no. 1, pp. 72-79, 1994.

[15] L.-J. Meng, M. Andritschky, and M. P. dos Santos, "The effect of substrate temperature on the properties of d.c. reactive magnetron sputtered titanium oxide films," Thin Solid Films, vol. 223, no. 2, pp. 242-247, 1993.

[16] M. Mayer, "SIMNRA, a simulation program for the analysis of NRA, RBS and ERDA," in AIP Conference Proceedings, vol. 475, pp. 541-544, 1999.

[17] L.-J. Meng and M. P. dos Santos, "The influence of oxygen partial pressure on the properties of DC reactive magnetron sputtered titanium oxide films," Applied Surface Science, vol. 68, no. 3, pp. 319-325, 1993.

[18] D. Mardare, C. Baban, R. Gavrila, M. Modreanu, and G. I. Rusu, "On the structure, morphology and electrical conductivities of titanium oxide thin films," Surface Science, vol. 507-510, pp. 468-472, 2002.

[19] K. J. Laidler, "The development of the arrhenius equation," Journal of Chemical Education, vol. 61, no. 6, pp. 494-498, 1984.

[20] K. C. Liddiard, "Thin-film resistance bolometer IR detectors," Infrared Physics, vol. 24, no. 1, pp. 57-64, 1984.

[21] M. Soltani, M. Chaker, E. Haddad, R. V. Kruzelecky, and J. Margot, "Effects of Ti-W codoping on the optical and electrical switching of vanadium dioxide thin films grown by a reactive pulsed laser deposition," Applied Physics Letters, vol. 85, no. 11, pp. 1958-1960, 2004.

[22] M. Vaziri, "Low-temperature conductivity of epitaxial ZnSe in the impurity band regime," Applied Physics Letters, vol. 65, no. 20, pp. 2568-2570, 1994.

[23] W. Meyer and H. Neldel, "A relation between the energy constant $\varepsilon$ and the quantity constant a in the conductivitytemperature formula for oxide," Zeitschrift fur Technische Physik, vol. 18, pp. 588-593, 1937.

[24] R. S. Crandall, "Defect relaxation in amorphous silicon: stretched exponentials, the Meyer-Neldel rule, and the StaeblerWronski effect," Physical Review B, vol. 43, no. 5, pp. 4057-4070, 1991.

[25] N. Mehta, "Meyer-Neldel rule in chalcogenide glasses: recent observations and their consequences," Current Opinion in Solid State and Materials Science, vol. 14, no. 5, pp. 95-106, 2010.

[26] K. Shimakawa and F. Abdel-Wahab, "The Meyer-Neldel rule in chalcogenide glasses," Applied Physics Letters, vol. 70, no. 5, pp. 652-654, 1997.

[27] J. Fortner, V. G. Karpov, and M.-L. Saboungi, "Meyer-Neldel rule for liquid semiconductors," Applied Physics Letters, vol. 66, pp. 997-999, 1995.

[28] G. F. Myachina, T. G. Ermakova, and V. A. Lopyrev, "Compensation effect in the electric conduction in some conjugated polymers," Physica Status Solidi A, vol. 81, no. 1, pp. 377-380, 1984.
[29] K. L. Ngai, "Meyer-Neldel rule and anti Meyer-Neldel rule of ionic conductivity conclusions from the coupling model," Solid State Ionics, vol. 105, no. 1-4, pp. 231-235, 1998. 

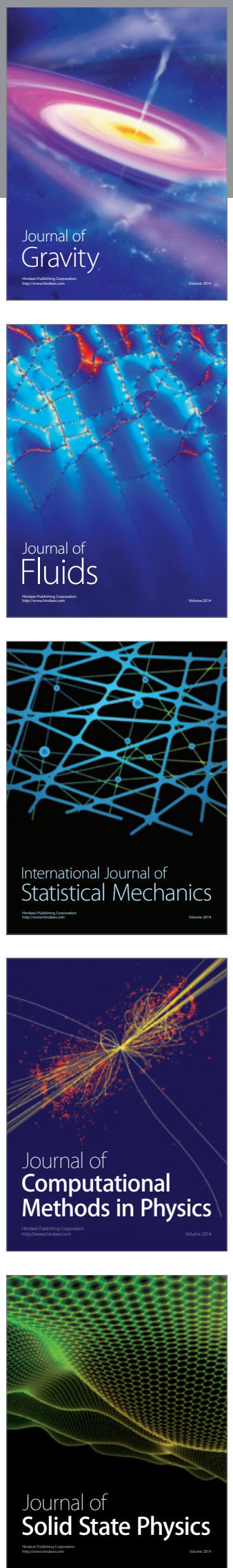

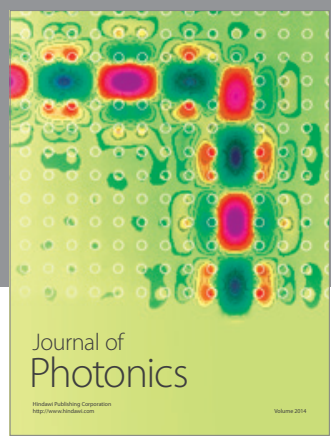

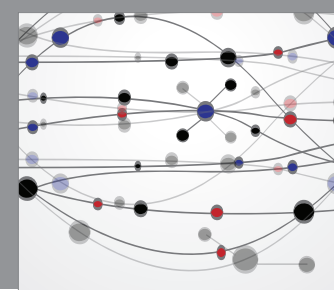

The Scientific World Journal

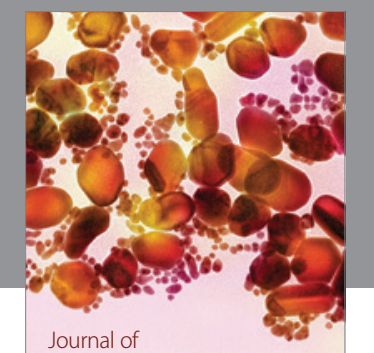

Soft Matter
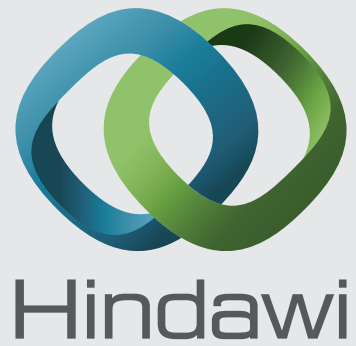

Submit your manuscripts at

http://www.hindawi.com
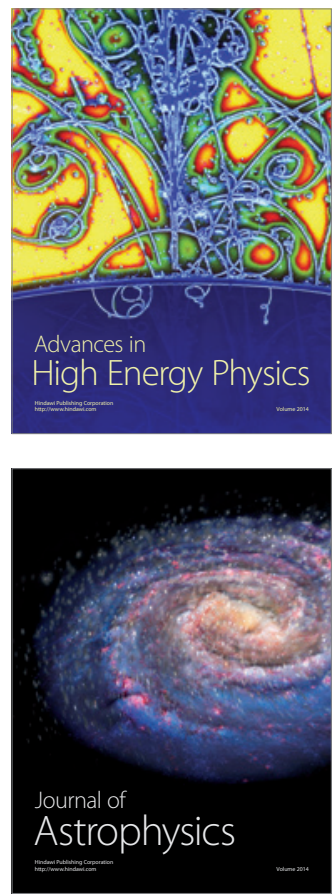
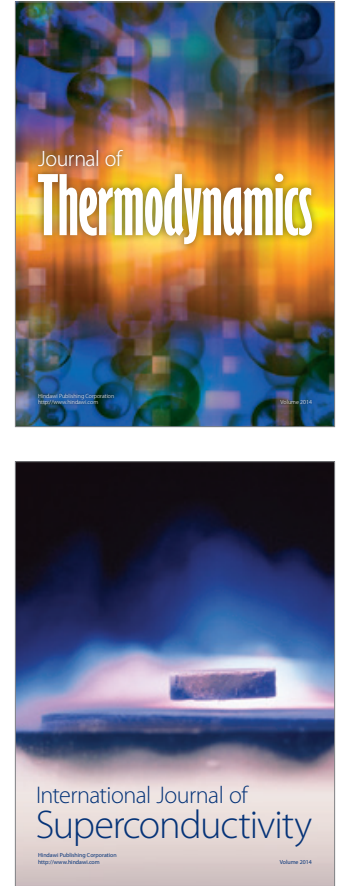
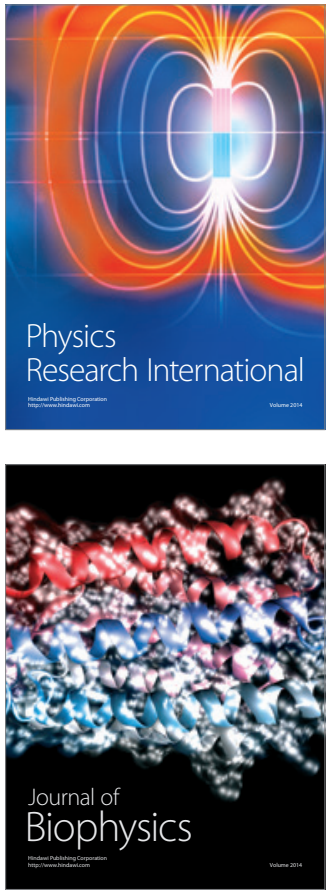
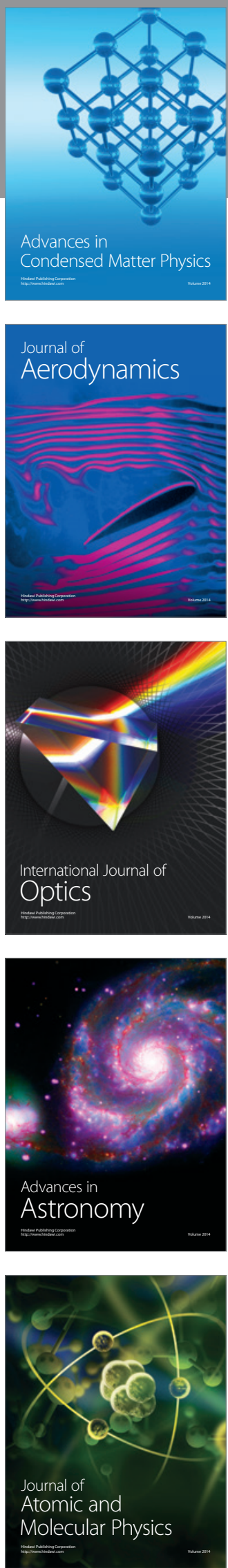